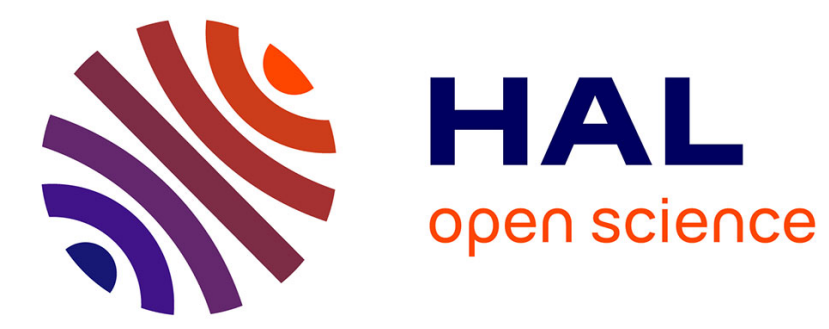

\title{
High-Strain-Rate Behavior of Several Types of Epoxy-Based Composites
}

\author{
V. Silvestrov, A. Plastinin
}

\section{To cite this version:}

V. Silvestrov, A. Plastinin. High-Strain-Rate Behavior of Several Types of Epoxy-Based Composites. Journal de Physique IV Proceedings, 1997, 07 (C3), pp.C3-459-C3-464. 10.1051/jp4:1997379 jpa00255536

\section{HAL Id: jpa-00255536 https://hal.science/jpa-00255536}

Submitted on 1 Jan 1997

HAL is a multi-disciplinary open access archive for the deposit and dissemination of scientific research documents, whether they are published or not. The documents may come from teaching and research institutions in France or abroad, or from public or private research centers.
L'archive ouverte pluridisciplinaire HAL, est destinée au dépôt et à la diffusion de documents scientifiques de niveau recherche, publiés ou non, émanant des établissements d'enseignement et de recherche français ou étrangers, des laboratoires publics ou privés. 


\title{
High-Strain-Rate Behavior of Several Types of Epoxy-Based Composites
}

\author{
V.V. Silvestrov and A.V. Plastinin \\ Lavrentyev Institute of Hydrodynamics, Lavrentyev Avenue 15, Novosibirsk 630090, Russia
}

\begin{abstract}
The mechanical behavior of several types of epoxy-matrix composites with uni- and two-directional reinforcement and one quasi-isotropic sintactic foam plastic with embedded hollow glass microspheres, subjected to dynamic loading at strain rates up to $100-10001 / \mathrm{s}$, is studied. For fiber reinforced composites, the ultimate strength and strain increase up to $2-2.5$ times relative static values while the elastic modulus along the filaments is independent of the strain rate. For a foam plastic, not only its compression strength and modulus of elasticity increase as the strain-rate increases but its fracture and the stress-strain behavior change too.
\end{abstract}

Résumé: On a étudié le comportement mécanique de quelques types de composites époxydes avec une armature mono- ou bidirectionnelle et une mousse plastique quasi-isotrope dans laquelle sont encapsulées des microsphères creuses en verre. Ces matériaux sont soumis à des vitesses de déformation dynamiques dont les valeurs vont de 100$1000 / \mathrm{sec}$. Pour les composites renforcés par des fibres directionnelles, les résistances limites de déformatión sont de 2-2.5 fois plus grandes que les valeurs statiques, alors que le module d'élasticité le long de fibres est indépendant de la vitesse de déformation. Pour une mousse plastique non seulement sa résistance à la compression et son module d'élasticité croissent avec la vitesse de déformation, mais la nature de sa rupture et le diagramme "contraintedéformation" changent aussi.

\section{INTRODUCTION}

In the last few years much consideration is given to the study of the effect of the high strain rate on the strength and elastic properties of epoxy-matrix composites [1]. It is well known that with increasing the strain rate to $100-1000 \mathrm{~s}^{-1}$ the strength and the modulus of elasticity of the thermoplastic resins increase by two to four times, variously and the stress-strain behavior of various thermoplastics at the high strain rates $[1,2]$. The incorporation of reinforcing elements of different types with the modulus much greater than that for matrix material may significantly affects the fracture and the stress-strain behavior of composites from elastoplastic peculiar to an epoxy matrix to elasto-brittle specific, for example, to glass inclusions.

The purpose of this paper is to describe the mechanical behavior and the fracture picture of a number of epoxy-matrix composites reinforced with elements made essentially of glass under loading at two strain rates $\dot{\varepsilon}$, low $\sim 10^{-3} \mathrm{~s}^{-1}$ and high $\sim 10^{3} \mathrm{~s}^{-1}$, and also with two types of reinforcing inclusions such as directional fibers and disperse spherical inclusions.

\section{TESTED MATERIALS AND EXPERIMENTAL TECHNIQUES}

This paper discusses the results obtained for the following epoxy-matrix composites (type of epoxy resin is ED-20): 1, glass/epoxy unidirectional composite rings with the fibers at 90-deg with circumferential direction; 2, an unidirectional fiberglass (type EF32-201) based on glass fibers $10-13 \mu \mathrm{m}$ 
a

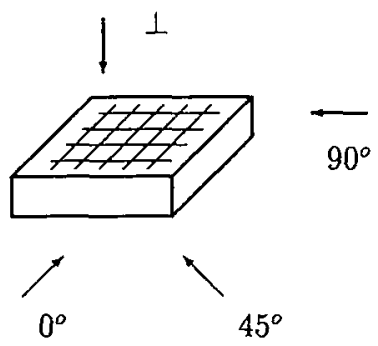

$\perp$

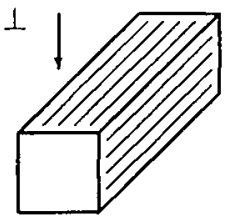

b

Figure 1: Scheme of testing for laminated (a) and unidirectional (b) composites. Arrows mark the loading direction.

in diameter ( $47 \%$ by volume); 3 , laminated textolite (type STEF) with straw glass cloth of linen weave reinforcement (up to $50 \%$ by volume); 4 , an aramid-glass-cloth-base-laminate textolite for which glass and aramid filaments are the warp and weft of cloth, respectively; 5 , graphite/epoxy composite with lay-up utilized unidirectional carbon filament plys $( \pm 45) n r ; 6$, a quasi-isotropic sintactic foam plastic, so-called spheroplastic, the epoxy-matrix composite with embedded hollow glass microspheres $20-80 \mu \mathrm{m}$ in diameter and density $\rho=0.63 \mathrm{~g} / \mathrm{cc}$.

Static data for materials either were taken from technical sources of information or determined by standard static test methods. Dynamic test samples for materials no. 2-6 were cylinders $D=6 \cdots 16$ $\mathrm{mm}$ in diameter and $L=2-8 \mathrm{~mm}$ in length. The ratio $L / D$ is ranged from 0.3 to 1 . The compusite samples for compressive loading were cut in three orientations in plane of reinforcement: $0^{\circ} .90^{\circ}$. and $45^{\circ}$, as well as in the direction normal to plys for laminated composites (Fig. 1). Based on experimental values of ultimate strengths in the longitudinal $R_{0}$, transverse $R_{90}$, and diagonal $l_{4 ;}$ directions, this made it possible to plot angle diagrams [3] illustrating the anisotropy of strength and elastic properties of tested composites at a dynamic loading.

Compression testing at the high strain-rate of loading was performed by using a compressive split Hopkinson bar technique with $20 \mathrm{~mm}$ measuring bars and a $50 \mu \mathrm{s}$ long stress pulse. For tulular material no. 1 the ring specimens $100 \mathrm{~mm}$ in inner diameter, $25-50 \mathrm{~mm}$ wide and $1.5 \mathrm{~mm}$ thick wer used, and high strain rate tension tests were realized by the expanding ring technique, analogous to that developed in [4]. In this case the tubular specimen was loaded by an internal pressure pulse applied explosively through a water.

Within the measurement accuracy for the dynamic stress strain curves their basic parameters. such as a modulus of elasticity $E$ and a ultimate compressive strength $R$, were independent of $L / D$. and hence according to [2] most experiments was performed for $L / D=0.5$. On account of the cssential scatter in the data for separate experiments the mean results of about 5-10 experiments for erer: loading condition were taken as mechanical characteristics of materials studied. The measurement. accuracy for the dynamic modulus $E$ fitting the data at $\varepsilon \leq 1 \%$ was $20 \%$, for the ultimate strength $R$ was $10 \%$, and for the ultimate strain before failure $\varepsilon_{\max }$ was $5 \%$.

\section{RESULTS AND DISCUSSION}

\subsection{Unidirectional composites}

Dynamic tension of a tubular composite. Figure 2 a gives the $\sigma, \varepsilon$ tension diagram for the material no. 1 at low and high strain rates. Within the measurement errors this plot is like the straight line and characterized by a modulus of elasticity $E=60 \pm 12 \mathrm{GPa}$ independent of the strain rate in the range from $10^{-4}$ up to $100-1200 \mathrm{~s}^{-1}$ (for static tests $E=65 \pm 5 \mathrm{GPa}$ ). The material both at static. and at dynamic loading is elastic-deformed down to failure. However with increasing the strain rate 

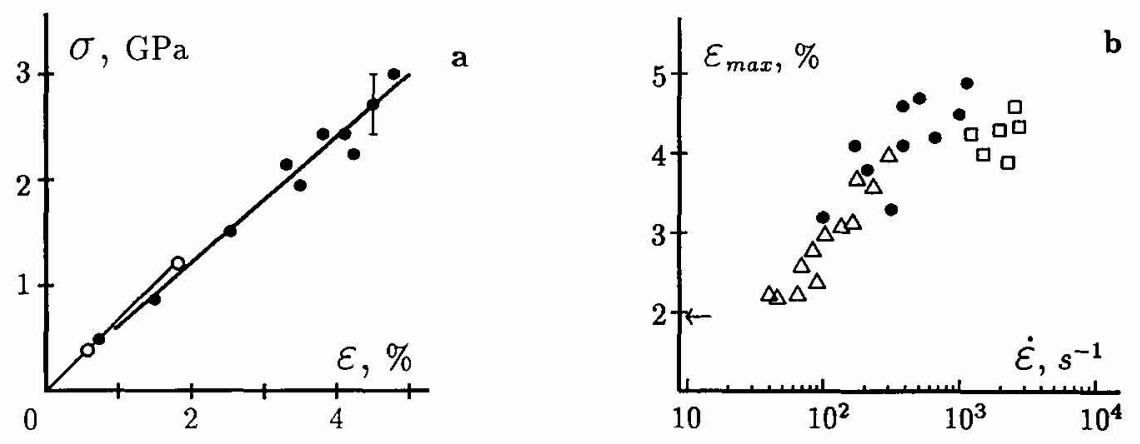

Figure 2: Tensile strain rate sensitivity for fiberglass rings.

(a) $\sigma, \varepsilon$ plot at static (o) and dynamic $(\bullet, \dot{\varepsilon}=200-12001 / \mathrm{s})$ loadings; (b) the $\dot{\varepsilon}$ dependence of ultimate strain, the arrow fits the static value, - this paper. The data obtained by other dynamic techniques [5] are as follows: $\triangle$ - hydropneumatic striker, $\square$-internal air blast loading.

above $\dot{\varepsilon} \sim 100 \mathrm{~s}^{-1}$ the ultimate strain (Fig. $2 \mathrm{~b}$ ) and tensile strength $\sigma_{\max }$ grow, for example, in static tests $\sigma_{\max }=1.2 \mathrm{GPa}$ while dynamic value achieves $3 \mathrm{GPa}$ at $\dot{\varepsilon} \simeq 1200 \mathrm{~s}^{-1}$.

The dynamic fracture of composite rings differs from that observed for static loading first of all by larger size of a zone of destruction, spanning practically the whole ring, whereas in static tests 1-2 hoop cracks alone can be observed. In dynamic tests the specimen is divided as though on separate circular elements which besides to pouring out a binder are broken off on circle in a number of places (Fig. 3). The similar results, such as the independence of the modulus of elasticity from the strain rate and the increase of the ultimate strain and stress about by 2 times, are also received for analogous unidirectional aramid/epoxy composite rings [5]. In both cases the dynamic ultimate strain of two composites essentiallv coincides with the static ultimate strain for reinforcing fibers.

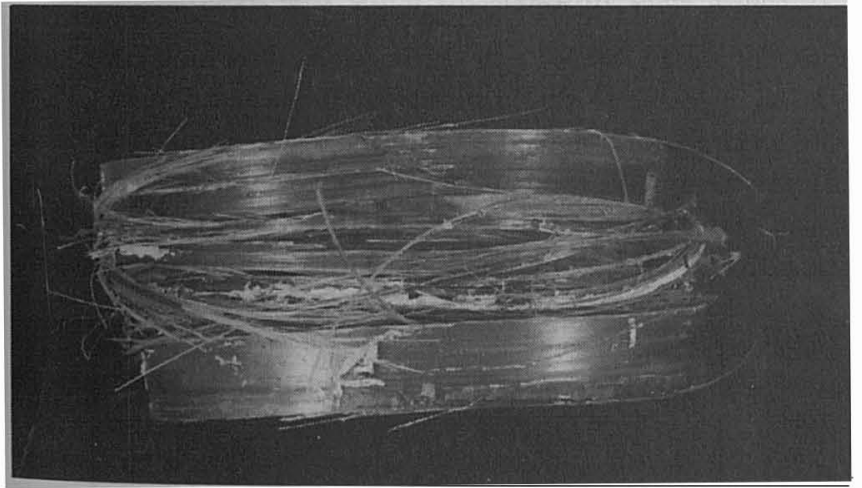

Figure 3: Photograph of fiberglass ring after dynamic testing.

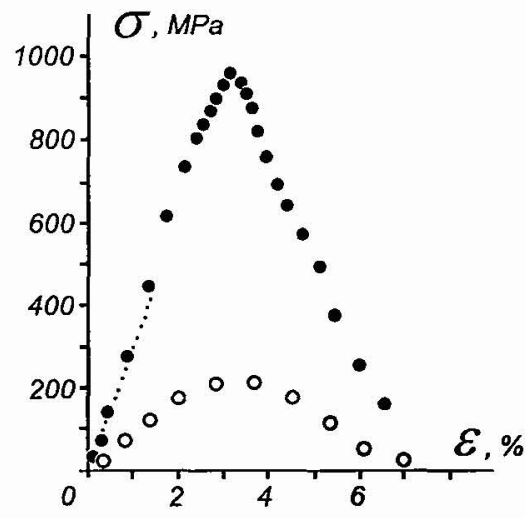

Figure 4: Comparison of loading intensity and orientation on the stress-strain behavior for unidirectional composite EF32-301. Loading orientations are at $0^{\circ}:-3000, \cdot-10001 / \mathrm{s}$; and $90^{\circ}: \circ-40001 / \mathrm{s}$.

Unidirectional glass-fiber reinforced composite. The dynamic stress-strain plots for compression of a material no. 2 lengthwise and cross fibres are shown in Fig. 4. A time intervals between points are $2(\bullet)$ and $4(0) \mu \mathrm{s}$. At more intensive loading (•) after achievement of ultimate strength the sample strain continues to grow, to that corresponds the falling parts of the diagrams, and the sample after experiment is destroyed. At less intensive loading $(\cdot)$ the sample is unloaded on a trajectory close to a loading path, i.e. the material is elastic-deformed, and the specimen after experiment remains whole. Falling parts of the plots have a certain physical sense and are apparently connected with the nonzero viscous resistance of a damaging material. In all case the slope of a dropping part of the 

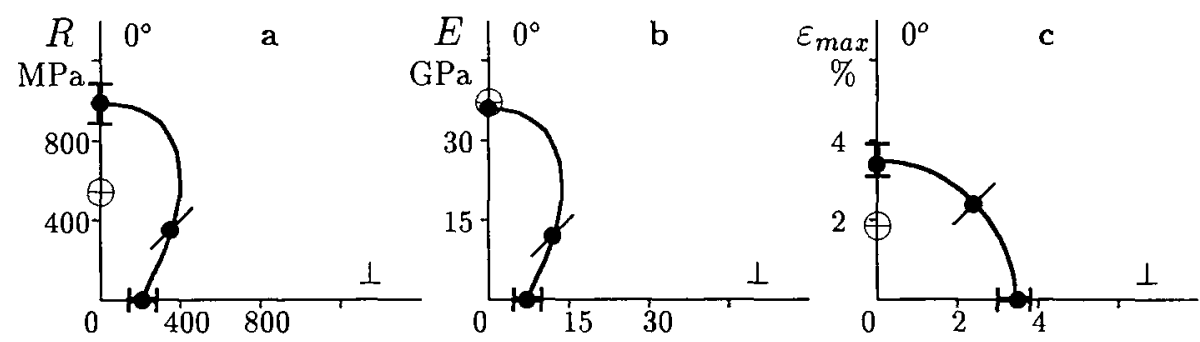

Figure 5: Effect of the loading angle on the strength (a), elastic modulus (b), and ultimate strain (c) for unidirectional composite. $\bullet-1000, \oplus-10^{-4} 1 / \mathrm{s}$, the curves are an approximation by formulas in [3].

$\sigma, \varepsilon$ plot is close on an absolutevalue to the slope of an ascending branch.

At longitudinal loading the failure of a composite occurs by its splitting into separate strands of fibers, and some of them being destroyed in addition across filaments. Apparently, the failure occur: through the fiber buckling in a pseudo-plastic matrix during compression.

The angle diagrams of the material at high strain rate are shown in Fig. 5. At high $\dot{\varepsilon}$ the dynamic ultimate compressive strength as $990 \mathrm{MPa}$ exceeds essentially the static strength $560 \mathrm{MPa}$ (Fig. 5a). however the dynamic modulus of elasticity equals $38 \mathrm{GPa}$, and coincides with static one (Fig. 5 . thus the ultimate strains being 3.5 and $2 \%$, respectively. For lengthwise and cross loading the ratius of dynamic strength and modulus of elasticity are: $R_{0} \simeq 5 R_{\perp}$ and $E_{0} \simeq 5 E_{\perp}$, the ultimate strilis are essentially coincident (Fig. $5 \mathrm{c}$ ).

\subsection{Laminated composites}

When passing from unidirectional to cloth-base-laminate materials the picture of failure is chariged because the filaments are good connected among themselves. The strength of layers on delamination appears to be less, than adhesion to a separate fiber, and the STEF material at dynamic test under the $0^{\circ}$ and $90^{\circ}$ schemes (Fig. 1a) damages at $\sigma \approx 430 \mathrm{MPa}(180 \mathrm{MPa}$ in static tests), breaking down into a stack of separate layers. Multiple delamination cracking in the laminate plane appears to be a major contributor in the ultimate failure. On the assumption, that the modulus is determined by fibers. orientated along the loading axis, the estimation by the mixture method gives $E_{0}=18 \mathrm{GPa}$ that essentially coincides with experimental static and dynamic values, $E_{0} \approx 19 \mathrm{GPa}$ (Fig. 6). Dynamic modulus of elasticity at loading orientations $0^{\circ}$ and $90^{\circ}$ is independent of the strain rate within the measurement accuracy.

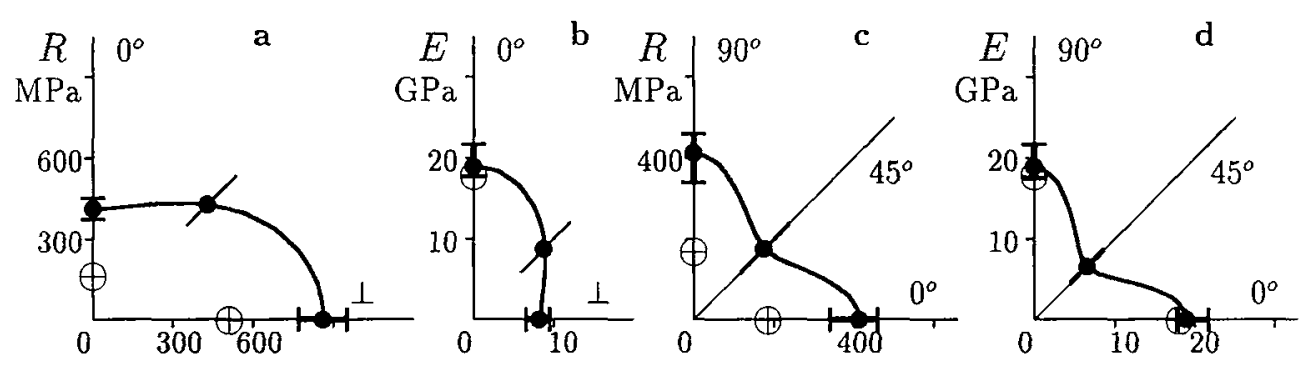

Figure 6: Angle diagrams for mechanical properties for STEF glass textolite at loading to $(\mathrm{a}, \mathrm{b})$ and in (c, d) plane of cloth plys. - - dynamic loading, $\dot{\varepsilon} \approx 500-10001 / \mathrm{s} ; \oplus$ - static loading; the curves are an approximation by formulas in [3]. 
In the transverse orientation to layers of glass fabric, the dynamic compressive strength of clothbased laminated composites, on the contrary, grows against unidirectional one. The samples are damaged on planes of the greatest shear stresses at $\sim 40^{\circ}-45^{\circ}$, as in case of a material EF 32-201, however in this case the failure planes cross filaments. $R_{1} \approx 860 \mathrm{MPa}$, which is two times greater, than that at lengthwise loading. In dynamic tests the ultimate strain increases by $1.5-2$ times, for instance, from 1.5 to $3.2 \%$ and from 5 to $10 \%$ for $0^{\circ}$ and $\perp$ orientations, respectively. As expected, the less strong material appear in test at $45^{\circ}$, where its strength properties manifest even less than for epoxy matrix.

Similar qualitative results, the significant anisotropy of dynamic compressive strength and modulus of elasticity and the influence of strain rate on the ultimate strain, are obtained by authors when researching the materials no. 4 and 5, i.e. the aramid-glass-cloth-base-laminate textolite and the low modulus graphite/epoxy composite [6]. The peculiarity of last composite is the greater discrimination of the $45^{\circ}$ orientation, i.e. if glass textolites in this loading direction show less strong and elastic properties by two times, then the graphite/epoxy composite so does by 6 times.

\subsection{Isotropic sintactic foam plastic}

Other qualitative stress-strain behavior at dynamic compression is observed for quasi-isotropic composite, material no. 6 . At static loading the stress-strain behavior of spheroplastic coincides to the typical elasto-brittle materials $[7,8]$.

Figure 7 presents compressive stress-strain curves of the spheroplastic for different $\dot{\varepsilon}$ obtained. Under quasi-static compression the composite remains in the brittle vitreous state until the fracture as the ultimate strain $\varepsilon_{\max }=4 \%$ occurs. The nonlinearity of the $\sigma, \varepsilon$ plot indicates that the glass point of the material is not much higher than the test room temperature, and the highly elastic strain is added to the pure-elastic strain. The modulus of elasticity determined from the slope of the $\sigma, \varepsilon$ plot for $\varepsilon \leq 1 \%$ is $E_{s t}=1.96 \pm 0.07 \mathrm{GPa}$.

With increasing the strain rate up to $800-3000 \mathrm{~s}^{-1}$, the spheroplastic passes into the state of the forced elasticity, and when the dynamic peak stress $\sigma_{*}$ is achieved, the material passes into the viscous-flow state characterized by the stress relaxation with an irreversible increase of strain up to $15-25 \%$. The influence of the strain rate on the strength of the spheroplastic is weaker than that of the matrix material. For the pure epoxy compound [9], the state of the forced elasticity is achieved even in quasi-static tests with $\dot{\varepsilon} \sim 0.02 \mathrm{~s}^{-1}$. The increase of the strain rate up to $10^{3} \mathrm{~s}^{-1}$ leads to almost a three fold increase of the peak stress and to the doubling of the strain $\varepsilon_{*}$ fitting the peak stress as much as $8 \%$. For the spheroplastic the $\varepsilon_{*}$ strain in dynamic tests remains essentially
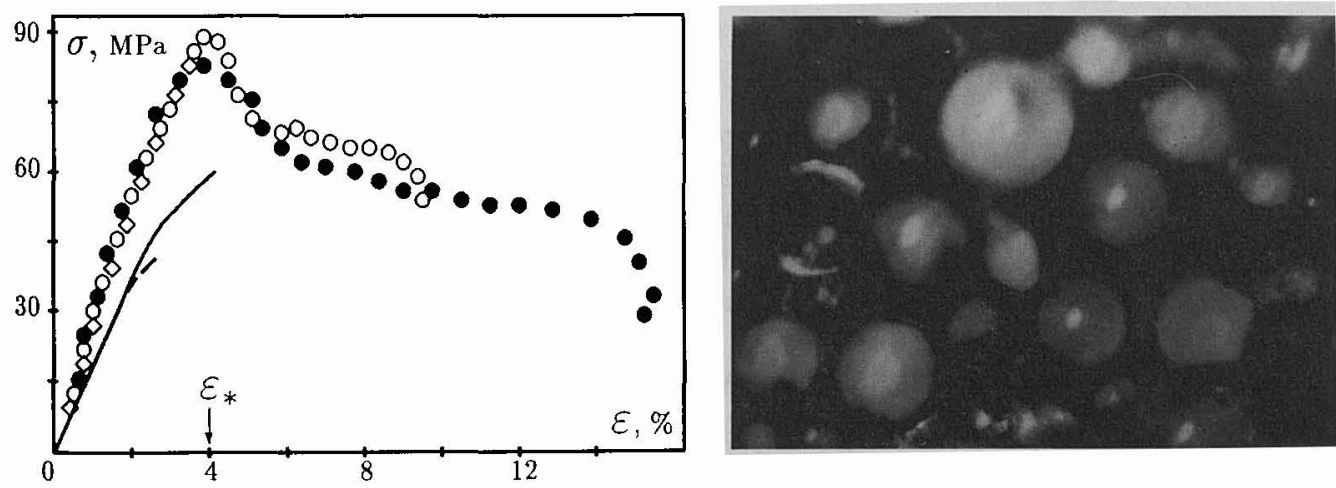

Figure 7: Effect of strain rate on the stress-strain behavior for spheroplastic at $\dot{\varepsilon}=2700(\bullet), 1600$ (o), $800(\circ), 10^{-2}$ (solid line), $5 \cdot 10^{-4}$ (dashed line) $\mathrm{s}^{-1}$.

Figure 8: Optical micrograph of dynamic fracture of spheroplastic, the image sizes are $235 \mu \mathrm{m} \times 175 \mu \mathrm{m}$. 
unchanged (Fig. 7), and the peak stress increases only by $1.5-2$ times.

The dynamic modulus of elasticity $E_{d}$ of the composite increases as high as $2.8 \pm 0.4$ (iPa. To) recheck this value, the velocity $c_{0}$ of a strain pulse with an amplitude of $0.1-1 \%$ and a half-height duration about $10 \mu$ s produced by an impact of a steel ball on the bottom of a square bar of the spheroplastic is measured [10]. It is obtained that $c_{0}=2.16 \pm 0.02 \mathrm{~km} / \mathrm{s}$, and the dynamic modinlus equals $E_{d}=\rho c_{0}^{2}=2.94 \pm 0.06 \mathrm{GPa}$ at $\dot{\varepsilon} \sim 100 \mathrm{~s}^{-1}$. The modulus of elasticity is the same as that found by processing the dynamic stress-strain curves.

Under the hydrostatic compression the fracture of a spheroplastic is caused by destruction of most glass microspheres [8]. Post mortem microscopy of tested samples damaged in dynamic i $151 \mathrm{~s}$ show that most of glass microspheres remain undamaged (Fig. 8), even though the acting stresse.. exceed substantially the hydrostatic strength of the material. The fracture occurs in the matrix material, that is by shear failure of the microsphere-matrix interface, above all in an adhesive larer. At dynamic loading its duration is very short and inadequate to destroy most of microspheres 1, dynamic buckling.

\section{SUMMARY}

With increasing strain rate from $\dot{\varepsilon} \sim 10^{-3}$ to $1000 \mathrm{~s}^{-1}$ for all epoxy-matrix composites studied t.l|c' ultimate strength and strain are significantly increased. The reinforcement type, such as directional fibers or fabric, or disperse inclusions, essentially affect the stress-strain response of tested composili': at dynamic loading.

For five composites strengthened by directed elements, unidirectional fibers or fabric, the fol lowing common features are observed: 1) the modulus of elasticity is independent of the strain rate within $20 \%$ accuracy; 2) glass/epoxy composites, aramid-glass/epoxy textolite and graphite/epoxy composite demonstrate an elasto-brittle behavior, irrespective of a loading direction; 3) a strong anisotropy of elastic and strength properties is observed for these composites as well as in static tests; 4) failure nature of materials depends on a loading direction.

For a quasi-isotropic composite, having the structure embedded with the hollow glass niicro spheres, the stress-strain behavior is varied at the high strain rate. At quasi-static compressive strain rates the composite remains in the brittle state until the failure. With increasing the slain rate the spheroplastic passes into the state of the forced elasticity and then into the viscous-flow statc characterized by a stress relaxation as the strain irreversibly increases. The strain corresponding to the peak stress coincides with the static one, while the modulus of the elasticity and the ultimate stress increase by 1.5 times. The increase of the modulus of the elasticity is proved by measuring the propagation velocity of the short strain pulse with $0.1-1 \%$ in amplitude.

\section{References}

[1] Groves S.E., Sanchez R.J., Lyon R.E., Brown A.E., Composite Materials: Testing and Desiyn (Eleventh Volume) ASTM STP 1206 (1993) pp. 162-176.

[2] Davies E.D.H., Hunter S.C., J. Mech. Phys. Solids 11(1963) 155-179.

[3] Tarnopol'skii Yu.M., Skudra A.M., Structural strength and deformability of glass-epoxy composites (Riga, 1966) pp. 81-87 (in Russian).

[4] Daniel I.M., Labedz R.H., Liber T., Exp. Mechanics 2(1981) 71-77.

[5] Aseev A.V., Gorshkov N.N, Demeshkin A.G., Makarov G.E., Plastinin A.V., Silvestrov V.V.. Stepanenko S.V., Mechanics of Composite Materials 2(1992) 127-133.

[6] Plastinin A.V., Silvestrov V.V., Mechanics of Composite Materials 6(1993) 776-782.

[7] Derunes Jr., Hoffman O., Trans. ASME, Ser.E, Appl. Mech. 3(1969) 181-189.

[8] Krzhechkovskii, P.G., Strength of Materials 1(1982) 110-115 (in Russian).

[9] Lindholm U.S., J. Mech. Phys. Solids 12(1964) 317-335.

(10) Plastinin A.V., Silvestrov V.V., Gorshkov N.N., Mech. of Composite Materials 3(1990) 451-4.51. 